\title{
Role of curcumin as anti-oxidant in nephrotoxicity
}

\begin{abstract}
Curcumin, a phenolic compound from the rhizome of the Curcuma longa linn (turmeric or curcuma) is a plant member of the ginger family (Zingiberaceae), endemic in tropical and subtropical fields of India, China and South East Asia. Ancient texts of Indian medicine explain the use of curcumin in inflammatory diseases, wound healing, and abdominal problems. It has been used as a dietary supplement for centuries and considered pharmacologically safe, recently has been known with anti-cancer and multiple properties, including anti-inflammatory, antioxidant and antiangiogenic. Also there are some evidences about preventive role of curcumin in nephrotoxicity and mephropathy, Antioxidant and anti-oxidative stress properties of curcumin proposed for its useful effect of curcumin in nephropathy this mini-review has been designed to discuss these aspects of this magic compound.
\end{abstract}

Keywords: crcumin, oxidative stress, anti-oxidant, nephrotoxicity, nephropathy

\author{
Volume 3 Issue I - 2017
}

\author{
Moammad Sheterpour,' Behnaz Bameri,' \\ Mahede Smadi,' Ali Ziar,' Ali Morad Heydari \\ Gorgi, ${ }^{2}$ Ramin Ataee ${ }^{1,3}$ \\ IPharmaceutical Sciences Research Center, Mazandaran \\ University of Medical Sciences, Iran \\ ${ }^{2}$ EDC center, Mazandaran University of Medical Sciences, Iran \\ ${ }^{3}$ Thalassemia research center, Mazandaran University of Medical \\ Sciences, Iran
}

\begin{abstract}
Correspondence: Ramin Ataee, Pharmaceutical Sciences Research Center, Mazandaran University of Medical Sciences, Km 18, Khazar Abad road, Payambar Azam buildings, Mazandaran University of Medical Sciences, Iran, Tel +989I I 3232804 , Email raminataeeI349@gmail.com
\end{abstract}

Received: August 01, 2016| Published: March 10, 2017

\section{General description}

Curcumin, a phenolic compound from the rhizome of the Curcuma longa linn (turmeric or curcuma) is a plant member of the ginger family (Zingiberaceae), endemic in tropical and subtropical fields of India, China and South East Asia. ${ }^{1}$ Curcumin or frolyl methane is a hydrophobic polyphenol derived and the chief component of the spice turmeric and is derived from the rhizome of the Curcuma longa. Its' uses are both orally and as a topical ointment to treat some disorders. It is widely used in traditional Indian medicine to treat hepatic disorders, anorexia, cough, diabetic wounds, rheumatoid arthritis, and sinusitis. Turmeric paste in slaked lime is a popular home remedy for the treatment of inflammation and wounds. ${ }^{1,2}$ Ancient texts of Indian medicine explain the use of curcumin in inflammatory diseases, wound healing, and abdominal problems. It has been used as a dietary supplement for centuries and considered pharmacologically safe, recently has been known with anti-cancer and multiple properties, including anti-inflammatory, ${ }^{3}$ antioxidant ${ }^{4,5}$ and antiangiogenic. ${ }^{6,7}$ In animal's studies, administration of this compound inhibited polyp formation and increased cell necrosis in colon cancer tssues. ${ }^{8}$ Among the potential pathways involved in these anti-cancer or anti-inflammatory properties, inhibition of nitric oxide synthase, activation of receptor tyrosine kinase and protein kinase $\mathrm{C}$ (PKC), alteration of the transcriptional factors c-jun/AP-1 and p53 as well as inhibition of arachidonic acid metabolism, lipoxygenase and cycloxygenase activity have been determined. ${ }^{9,10}$ Also there are some studies to combine it with others anti-cancer herbal chemical medicines such as green tea to induce a strong inhibitory effect in oral cancer and non-small cell lung cancer. ${ }^{10}$

\section{Turmeric rhizome is including three analog colours}

Curcumin, demethoxy curcumin (DMC) and bis demethoxy curcumin (BDMC) which collectively are called curcuminoids. These compounds are the cause of the yellow colour in turmeric and differ in the position of the methoxy groups on the aromatic ring (Figure 1). ${ }^{2}$
Among of the three curcuminoid, curcumin in turmeric is the most abundant 7 . Several studies have reported that curcumin turmeric has considerable biological properties including antitumor and anticancer activity, reducing blood and liver cholesterol levels, boosting immune function, cardiovascular disease deterrence, and prevention of damage to biological membranes against oxidation, antiinflammatory and reduce rheumatoid arthritis. ${ }^{2}$<smiles>COc1cc(/C=C/C(=O)CC(=O)/C=C/c2ccc(/C=C/C(=O)/C=C(O)/C=C/c3ccc(O)c(OC)c3)c(OC)c2)ccc1O</smiles>

Figure I I: Keto from of curcumin; II: Enol from of curcumin.

\section{Anti-oxidant and anti oxidative stress activity of curcumin}

Also it has been shown that curcumin is a bifunctional antioxidant ${ }^{11}$ because of its properties to react directly with reactive species and up-regulation of many cytoprotective and antioxidant proteins. Also it can scavenger superoxide anion $\left(\mathrm{O}_{2}\right),{ }^{12,13}$ hydroxyl radicals $(\mathrm{OH})$, $\mathrm{H}_{2} \mathrm{O},{ }^{13,14}$ singlet oxygen, ${ }^{15}$ nitric oxide, ${ }^{16,17}$ peroxynitrite ${ }^{18}$ and peroxyl radicals (ROO2).$^{14}$ So these mechanisms can confirm some of the cytoprotective effects of this herbal compound. The phenolic groups in the structure of curcumin can explain its properties to react with reactive oxygen species (ROS) and reactive nitrogen species (RNS) and may probably explain one of the mechanisms through which it protects the epithelial cells of renal tubules from oxidative damage 
induced by $\mathrm{H}_{2} \mathrm{O}_{2} \cdot{ }^{19}$ The indirect antioxidant activity of curcumin is explained by its ability to induce the expression of cytoprotective proteins such as superoxide dismutase (SOD), catalase (CAT), glutathione reductase (GR), glutathione peroxidase (GPx), heme oxygenase 1 (HO-1), glutathione-S-transferase (GST), NAD(P)H: quinone oxidoreductase 1 (NQO1) and $\gamma$-glutamylcysteine ligase $(\gamma \mathrm{GCL}){ }^{20}$

Oxidative stress is an imbalance between free radicals and antioxidant systems to cause chronic diseases such as cancer, diabetic nephropathy or neuropathy, alzheimer's and Parkinson's diseases. ${ }^{2}$ Reactive oxygen species (ROS) and free radicals such as hydroxyl radicals and hydrogen peroxide are produced in the human body during normal metabolic pathways and exposure to exogenous stress such as ionizing radiation and air pollutions which can induce adverse effects on the normal physiological activity of cells. The body's system has antioxidant defense and enzymes which neutralize the ROS. Unfortunately, increasing of ROS levels or decreasing ability for detoxification of the antioxidant defense system can lead to increased oxidative stress and turn cell damage and death. ${ }^{21-23}$ Antioxidants have protective effects on the cells so that they can protect it from damages caused by unexpectedly and uncontrollably produced ROS. ${ }^{24,2}$ Although a number of synthetic and natural antioxidant compounds have already been identified, the search for effective antioxidant and lesser side effects and toxicity is being continued. Turmeric is one of the plants that contain natural active ingredients and safe. ${ }^{24}$

\section{Role of curcumin in nephrotoxicity}

According o some studies, preventive role for curcumin in some nephrotoxicities conditions has been known For example, curcumin treatment in an animal model of diabetic nephropathy diminished proteinuria and improved creatinine clearance. ${ }^{20}$ Also, it attenuated oxidative stress by reducing levels of nicotinamide adenine dinucleotide phosphate (NADPH) ${ }^{20}$ Also according to some other studies, it was suggested that, the nephroprotective effect of curcumin was related to the downregulation of the profibrotic cytokines vascular endothelial growth factor (VEGF), TGF- $\beta$, CTGF and osteopontin as in extracellular matrix proteins fibronectin and collagen IV. ${ }^{20}$ Cellular signalings such as inhibition of nuclear factor kappa-light-chain enhancer of activated B cells $(\mathrm{NF}-\kappa \mathrm{B})^{26,27}$ and decrease of macrophage infiltration ${ }^{27}$ histone acetyltransferase $\mathrm{p} 300$ protein and oxidative stress ${ }^{26}$ also these mechanisms may be as those, through which the curcumin protects against diabetic nephropathy. Also, Waseem M et al. ${ }^{28}$ at 2013 in a research has shown that curcumin could have protective effect in acute nephrotoxicity model induced with cisplatin in rat and reduced lipid peroxidation and protein carbonyl levels. ${ }^{28}$ In Ukei M et al., ${ }^{29}$ study at 2013 in mice who received curcumin 10mg/ $\mathrm{kg}$ with cisplatin has been shown, The levels of inflammation factors as tumor necrosis factor (TNF)- $\alpha$ and monocyte chemoattractant protein (MCP)-1 have been decreased. ${ }^{29}$ Also in a research by Manikandan R et al at 2011, in acute nephrotoxicity model of gentamycin, it was demonstrated that curcumin could reduced iNOS and NF-KB expression ${ }^{30}$ and in a study at 2009 in Turkey by Cekmen $\mathrm{M}$ et al. ${ }^{31}$ curcumin reduced $\mathrm{BUN} / \mathrm{Cr}$ and MDA in rats in a model of acetaminophen nephrotoxicity. ${ }^{31}$ Also we have a study similar to Cekmen $\mathrm{M}$ et al., ${ }^{31}$ about protective role of curcumin in acute and chronic nephrotoxicity induced by lithium with similar MDA and histopatholgical results also by attenuating BUN and creatinine levels in rats by which its' results are under publication.

\section{Conclusion}

According to this minireview we can conclude that curcumin because of its' anti-oxidant and anti-oxidative stress properties can have protective effects against many diseases especially nephropathies as in diabetes or other chemical intoxications.

\section{Acknowledgements}

We appreciate Mrs. Maryam Alizadeh for her efforts in lab arrangement and nice collaboration.

\section{Conflict of interest}

The author declares no conflict of interest.

\section{References}

1. Asouri M, Ahmadi A, Amini A, et al. Antioxidant and Free Radical Scavenging Activities of Curcumin. Asian Journal of Chemistry. 2013;25(13):7593-7595.

2. Nasri Nasrabadi N, Seyed Azizi ZM, Ataie A, et al. Evaluation of antidepressant-like activity of curcumin by using forced swimming test compared with Imipiramine. Universal Journal of Pharmacy. 2014;3(4):42-45.

3. Huang MT, Lysz T, Ferraro T, et al. Inhibitory effects of curcumin on in vitro lipoxygenase and cyclooxygenase activities in mouse epidermis. Cancer Res. 1991;51(3):813-819.

4. Jovanovic SV, Boone CW, Steenken S, et al. How curcumin works preferentially with water soluble antioxidants. $\mathrm{J} \mathrm{Am} \mathrm{Chem} \mathrm{Soc.}$ 2001;123(13):3064-3068

5. Sandur SK, Ichikawa H, Pandey MK, et al. Role of pro-oxidants and antioxidants in the anti-inflammatory and apoptotic effects of curcumin (diferuloylmethane). Free Radic Biol Med. 2007;43(4):568-580.

6. Yoysungnoen P, Wirachwong P, Bhattarakosol P, et al. Effects of curcumin on tumor angiogenesis and biomarkers, COX-2 and VEGF, in hepatocellular carcinoma cell-implanted nude mice. Clin Hemorheol Microcirc. 2006;34(1-2):109-115.

7. Lin YG, Kunnumakkara AB, Nair A, et al. Curcumin inhibits tumor growth and angiogenesis in ovarian carcinoma by targeting the nuclear

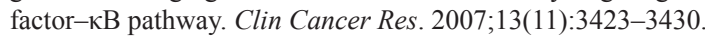

8. Zafar S, Hampton J, Keck R, et al. Curcumin prevents AY27 bladder transitional cell tumor growth in Fisher 344 rats. J Urol. 2003;169:194

9. Choudhuri T, Pal S, Agwarwal ML, et al. Curcumin induces apoptosis in human breast cancer cells through p53-dependent Bax induction. FEBS Lett. 2002;512(1-3):334-340.

10. Squires MS, Hudson E, Howells L, et al. Relevance of mitogen activated protein kinase (MAPK) and phosphotidylinositol-3-kinase/ protein kinase $\mathrm{B}$ (PI3K/PKB) pathways to induction of apoptosis by curcumin in breast cells. Biochem Pharmacol. 2003;65(3):361-376.

11. Kostova D, Talalay P. Direct and indirect antioxidant properties of inducers of cytoprotective proteins. Mol Nutr Food Res. 2008;52 Suppl 1:S128-S138.

12. SreejayanN, Rao MN. Free adical scavenging activity of curcuminoids. Arzneimittelforschung. 1996;46(2):169-171.

13. Ak T, Gulcin I. Antioxidant and radical scavenging properties of curcumin. Chem Biol Interact. 2008;174(1):27-37.

14. Barzegar A, Moosavi AA. Intracellular ROS protection efficiency and free radical-scavenging activity of curcumin. PLoS One. 2011;6(10):e26012. 
15. Das KC, Das CK. Curcumin (diferuloylmethane), a singlet oxygen ((1) $\mathrm{O}(2))$ quencher. Biochem Biophys Res Commun. 2002;295(1):62-66.

16. Sreejayan, Rao MN. Nitric oxide scavenging by curcuminoids. J Pharm Pharmacol. 1997;49(1):105-107.

17. Sumanont Y, Tohda M, Vajragupta O, et al. Evaluation of the nitric oxide radical scavenging activity of manganese complexes of curcumin and its derivative. Biol Pharm Bull. 2004;27(2):170-173.

18. Kim JE, Kim AR, Chung HY, et al. In vitro peroxynitrite scavenging activity of diarylheptanoids from Curcuma longa. Phytother Res. 2003;17(5):481-484.

19. Augustyniak A, Cipak A, Duburs G, et al. Natural and synthetic antioxidants: an updated overview. Free Radic Res. 2010;44:12161262.

20. Trujill J, Molina Jijó E, Andérica Romer AC, et al. Renoprotective effect of the antioxidant curcumin. Redox Biol. 2013;17(1):448-456.

21. Aggarwal BB, Kumar A, Bharti AC. Anticancer potential of curcumin: preclinical and clinical studies. Anticancer Res. 2003;23(1A):363-398.

22. Ataie A, Sabetkasaei M, Haghparast A, et al. Curcumin exerts neuroprotective effects against homocysteine intracerebroventricular injection-induced cognitive impairment and oxidative stress in rat brain. J Med Food. 2010;13(4):821-826.

23. Jovanovic SV, Boone CW, Steenken S, et al. How curcumin works preferentially with water soluble antioxidants. $J$ Am Chem Soc. 2001;123(13):3064-3068

24. Wang YJ, Pan MH, Cheng AL, et al. Stability of curcumin in buffer solutions and characterization of its degradation products. Journal of Pharmaceutical and Biomedical Analysis. 1997;15(12):1867-1876.
25. Huang MT, Ma W, Lu YP, et al Effects of curcumin demethoxycurcumin, bisdemethoxycurcumin and tetrahydrocurcumin on 12-O-tetradecanoylphorbol-13-acetate-induced tumor promotion. Carcinogenesis. 1995;16(10):2493-2497.

26. Chiu J, Khan ZA, Farhangkhoee H, et al. Curcumin prevents diabetesassociated abnormalities in the kidneys by inhibiting p300 and nuclear factor-kappaB. Nutrition. 2009;25(9):964-972.

27. Soetikno, Veeraveedu PT, Zhandavarayan RA, et al. Curcumin ameliorates macrophage infiltration by inhibiting $\mathrm{NF}-\kappa \mathrm{B}$ activation and proinflammatory cytokines in streptozotocin induced-diabetic nephropathy. Nutrition \& Metabolism. 2011;8(1):35.

28. Waseem, Kaushik P, Parvez S. Mitochondria-mediated mitigatory role of curcumin in cisplatin-induced nephrotoxicity. Cell Biochem Funct. 2013;31(8):678-684

29. Ueki M, Ueno M, Morishita J, et al. Curcumin ameliorates cisplatininduced nephrotoxicity by inhibiting renal inflammation in mice. $J$ Biosci Bioeng. 2013;115(5):547-551.

30. Anikandan R, Thiagarajan R, Priyadarsini A, et al. Ameliorative effects of curcumin against renal injuries mediated by inducible nitric oxide synthase and nuclear factor kappa B during gentamicin-induced toxicity in Wistar rats. Eur J Pharmacol. 2011;670(2-3):578-585.

31. Cekmen M, Ozbek E, Simsek A, et al. Curcumin prevents oxidative renal damage induced by acetaminophen in rats. Food chem Toxicol. 2009;47(7):1480-1484 